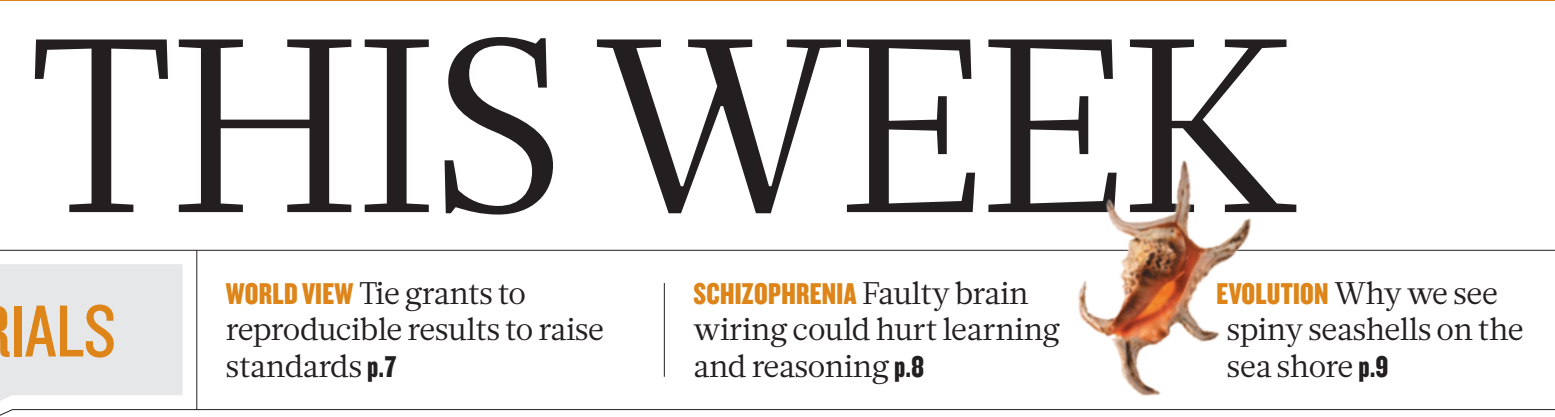

EDITORIALS ie grants to standards p.7

\title{
A record made to be broken
}

\section{Japan's major science-funding agency has a clean record when it comes to research fraud. Now is the time for it to step up and resolve a long-running case of alleged scientific misconduct.}

$\int$ apan's major funder of big science, the Japan Science and Technology Agency (JST), is either very good at picking honest scientists, or does not look very hard for evidence to the contrary. The total number of fraud cases confirmed by the JST since its beginnings in 1957 — an organization that delivered $¥ 87.8$ billion (US\$942 million) in research funding last year - is zero.

The US National Institutes of Health reports a dozen or so such cases every year. Elsewhere in Japan, there has been a spate of highprofile cases of fraud in recent years - including that of Yoshitaka Fujii, an anaesthesiologist who currently has the highest number of retractions by a single author. The JST's perfect record would seem to be against the odds.

A long-running case typifies the problems. Akihisa Inoue, retired president of Tohoku University in Sendai, has been hounded by accusations of scientific misconduct for years.

There is no evidence that Inoue has committed any misconduct, and he denies manipulating any data. He is one of the world's leading experts in metallic glasses - materials that are more elastic and more resistant to corrosion than metals - and has published more than 2,500 papers on the subject. He has previously told Nature that other researchers may simply lack the skills and experience to reproduce some of his lab's results (see Nature 470, 446-447; 2011).

There is a clear need for the JST to resolve the situation. Questions over Inoue's work were first raised by an anonymous whistle-blower nearly six years ago, and the case touches on research going back two decades (see Nature 483, 259; 2012). There have been many complicated twists. Tao Zhang, a co-author with Inoue on several papers, says that the documents and metallic glass samples that could have settled the matter were lost when a container carrying his belongings back to his home in China fell into the sea. A committee set up by Tohoku University in 2007 to determine whether to investigate the misconduct allegations was dominated by university administrators who had previously been promoted to their posts by Inoue. The committee's conclusion - that there was no need to investigate - led to charges of conflict of interest by an economist and other colleagues at the university, who raised questions with journal editors. A series of corrections have been issued about the relevant papers.

Last year, a separate committee convened by the JST - which gave Inoue $¥ 1.8$ billion for a five-year project starting in 1997, during which several of the problematic papers were produced - reported that although they couldn't find evidence of misconduct, a closer look was justified. So last spring, the JST formally requested that the university investigate. Twelve months on, neither the university nor the JST would confirm whether an investigation was under way, who would be on the investigation committee or when it would start and end.

There is no deadline by which any investigation must report back, and if Tohoku University fails to respond, the JST can take no action other than to ask again. The university, which might have to return some or all of the money if it discovers misconduct, again faces a conflict of interest in addition to the embarrassment of an investigation. Doing nothing apparently has no consequences. And it is one way, now and in the future, to ensure that the JST will keep its perfect record.

\section{Against the law}

\section{Behaviours proposed for black holes conflict with the laws of physics.}

$\mathrm{N}$ ever let it be said that Nature does not address the science questions that are on the lips of researchers. On page 20, a News Feature poses the conundrum: will an astronaut who falls into a black hole be crushed or burned to a crisp? The answer, according to the disappointing end to the Disney film The Black Hole (Gary Nelson; 1979 ) is neither: the astronaut will go on a psychedelic trip through a (possibly metaphorical) hell and heaven. The answer according to physicists in 2013 is even more of a let-down: they don't know.

The European particle-physics laboratory CERN, located near Geneva in Switzerland, has had a mixed experience with black holes: various challenges to its Large Hadron Collider over the years have focused on the (very small) chance that it could create (very small) black holes that would destroy the world. So the CERN press office must have looked on nervously as physicists gathered there last month to address the mysterious fate of our unfortunate astronaut. There is more at stake than the grisly demise of a single free-floating space traveller. The physics is complicated but the take-home message is this: if the astronaut fries, then Einstein's framework of general relativity goes up in smoke with it; if the astronaut is crushed and torn by the black hole's internal variation in gravity, then quantum mechanics is wrong.

So which is it, relativity or quantum theory; heaven or hell? Debate continues. One compromise has the astronaut hang around outside the black hole to hoover up some quantum information as it leaks, use it to do some maths and then jump in to see if either theory is right. So far so good (for the laws of physics if not the astronaut, who perishes either way) except that the maths is so difficult that, by the time scientists have an answer, the black hole will have evaporated beneath them. Now that would make for a better ending, at least for the astronaut. Disney, which is said to be remaking its film, should take note. 